\title{
A case for serial examination of sputum inflammatory cells
}

\author{
A.G. Wong, I.D. Pavord, M.R. Sears, F.E. Hargreave
}

A case for serial examination of sputum inflammatory cells. A.G. Wong, I.D. Pavord, M.R. Sears, F.E. Hargreave. (CERS Journals Ltd 1996.

ABSTRACT: In the case reported, serial evaluation of sputum inflammatory cell counts made it possible to identify an unusual series of events in a man with eosinophilic bronchitis. The patient initially presented with a productive cough, which did not respond to treatment with antibiotics or high-dose inhaled corticosteroids. A diagnosis of eosinophilic bronchitis was made after demonstration of intense sputum eosinophilia.

When inhaled corticosteroids were stopped, symptoms and sputum eosinophilia became worse and airway hyperresponsiveness developed. Both abnormalities were reversed by a course of prednisone. When the prednisone was stopped the productive cough recurred but on this occasion sputum examination suggested a different disease process and the symptoms resolved after a course of co-trimoxazole. The patient has subsequently remained well on no treatment with little or no sputum eosinophilia.

Eur Respir J., 1996, 9, 2174-2175.
Asthma Research Group, Dept of Medicine, St Joseph's Hospital and McMaster University, Hamilton, Ontario, Canada.

Correspondence: F.E. Hargreave, Firestone Regional Chest and Allergy Unit, St Joseph's Hospital, 50 Charlton Avenue East, Hamilton, Ontario, Canada L8N 4A6

Keywords: Airway responsiveness eosinophilic bronchitis sputum cell counts

Received: October 51995

Accepted after revision March 91996

AGW was supported by a grant from the Firan Foundation.
There are many causes of airway inflammation but the consequences both in terms of symptoms and disordered airway physiology are limited, so that the accurate diagnosis is not always straightforward. New techniques for assessing sputum differential cell counts [1] offer the prospect of identifying different types of airway inflammation, although how clinically useful this is remains to be determined. We report a case where serial measurements of sputum differential counts were invaluable both in recognizing different patterns of airway inflammation resulting in similar symptoms, and in monitoring the effects of treatment.

\section{Case report}

A 62 year old male pharmaceutical sales manager presented on January 19, 1993 with a 2 month history of a troublesome cough, some mucoid sputum and mild wheeze. He had no prior history of asthma, rhinitis, sinusitis or gastro-oesophageal reflux. There was little improvement following a course of ciprofloxacin or on treatment with inhaled budesonide $400 \mu \mathrm{g}$, nedocromil sodium $4 \mathrm{mg}$, salbutamol $200 \mu \mathrm{g}$ and ipratropium bromide $40 \mu \mathrm{g}$, each taken four times daily. Physical examination and chest radiograph were normal and sputum cultures were negative. The forced expiratory volume in one second (FEV1) was $3.0 \mathrm{~L}$ (86\% predicted) and slow vital capacity (SVC) was $4.0 \mathrm{~L}$ ( $89 \%$ pred), and a methacholine inhalation test carried out using a standard protocol [2] revealed normal airway responsiveness (table 1). Allergy skin-prick tests gave a wheal and flare response to extracts of tree, grass and ragweed pollen but were negative for other common aeroallergens, including Aspergillus fumigatus.

Given the apparent lack of response to treatment, medications were stopped. However, sputum differential cell

Table 1. - Summary of data over a 58 week period

\begin{tabular}{|c|c|c|c|c|c|c|c|c|c|}
\hline & \multicolumn{9}{|c|}{ Weeks } \\
\hline & 0 & 1 & 3 & 4.5 & 6 & 9 & 13 & 17 & 58 \\
\hline Cough & Yes & Yes & Yes & Yes & No & No & No & No & No \\
\hline Sputum eosinophils\# $\%$ & 76 & 89 & 3.0 & 2.9 & 2.1 & & 9.5 & & 0.9 \\
\hline Sputum neutrophils ${ }^{+} \%$ & 7.1 & 2.3 & 3.0 & 36 & 49 & & 52 & & 39 \\
\hline FEV1 L & 3.0 & 2.8 & 3.3 & 3.4 & & 3.5 & 3.3 & 3.1 & 3.3 \\
\hline$\%$ pred & 86 & 80 & 94 & 97 & & 100 & 94 & 89 & 94 \\
\hline VC L & 4.0 & 3.7 & 4.1 & 4.0 & & 4.2 & 3.9 & 3.9 & 4.0 \\
\hline$\%$ pred & 91 & 84 & 93 & 91 & & 95 & 89 & 89 & 91 \\
\hline $\mathrm{PC} 20 \mathrm{mg} \cdot \mathrm{mL}^{-1}$ & $>16$ & 2.7 & & & & $>16$ & & $>16$ & $>16$ \\
\hline Treatment & & P, B & B & B, C & $\mathrm{B}$ & $\mathrm{B}$ & & & \\
\hline
\end{tabular}

\#: normal 0.2-0.7\%; +: normal 13-35\%. FEV1: forced expiratory volume in one second (predicted $3.5 \mathrm{~L}$ ); VC: vital capacity (predicted $4.4 \mathrm{~L}$ ); PC20: provocative concentration of methacholine to cause a $20 \%$ fall in $\mathrm{FEV}_{1}\left(\mathrm{normal}>16 \mathrm{mg} \cdot \mathrm{mL}^{-1}\right.$ ); $\%$ pred: percentage of predicted value; $\mathrm{P}$ : prednisolone; B: budesonide; C: co-trimoxazole. 
counts from a spontaneously produced sample processed using 1\% dithiothrietol to facilitate cell dispersion, as described by PopOv et al. [1], revealed a markedly raised eosinophil count of $76 \%$ (normal $<2 \%$ ), suggesting eosinophilic bronchitis [3]. One week after stopping therapy, the cough became more severe, spirometry deteriorated and mild airway hyperresponsiveness to methacholine developed. Sputum analysis revealed a higher eosinophil count (table 1). The patient was treated with prednisone, $30 \mathrm{mg}$ daily, for 5 days followed by a $5 \mathrm{mg} \cdot$ day $^{-1}$ reduction, during which time inhaled budesonide $400 \mu \mathrm{g}$ b.i.d. was added. His symptoms resolved completely.

On February 15, 7 days after stopping prednisone, cough and sputum recurred along with fever, anorexia and fatigue. Clinical examination, chest radiograph and spirometry were normal. The full blood count was normal, erythrocyte sedimentation rate (ESR) $20 \mathrm{~mm} \cdot \mathrm{h}^{-1}$, and autoantibodies were not detected. Sputum neutrophil and eosinophil differential cell counts were both normal at near normal 3\%. Despite an increase in budesonide to $400 \mu \mathrm{g}$ q.i.d. for 10 days, the patient remained symptomatic. Further examination of his mucoid sputum revealed an elevated, but still normal, neutrophil count and near normal eosinophil count. These results suggested another aetiology for the cough. Sputum cultures revealed no pathogens. Treatment with inhaled budesonide was continued at $400 \mu \mathrm{g}$ b.i.d. and a 10 day course of co-trimoxazole was added. This was followed by complete clearing of his symptoms. He has since remained well and has been off budesonide for 11 months, without symptoms or a significant recurrence of induced sputum eosinophilia, abnormal spirometry or airway hyperresponsiveness.

\section{Discussion}

This case was thought to be interesting and worthy of report for several reasons. Firstly, serial measurements of sputum cell counts were used to demonstrate different patterns of airway inflammation and to guide therapy. Secondly, there was apparent progression from a typical case of eosinophilic bronchitis to eosinophilic bronchitis with features of asthma following withdrawal of inhaled corticosteroid therapy. Finally, a complete and long-lasting remission was achieved after a short course of oral prednisone.

Refinements in the methodology of sputum collection [4] and differential cell counting over the past 7 yrs have resulted in a technique that gives reliable and repeatable cell counts that are suitable for serial measurement and are potentially of great value in the investigation of airway inflammation [2, 4-7]. This potential value is wellillustrated by the current case, where demonstration of the nature of the airway inflammation at presentation by a simple and noninvasive test enabled a firm diagnosis to be made early, and was of considerable help in guiding management. This was particularly the case at the time of relapse, when sputum cell counts suggested that the recurrence of symptoms was not due to eosinophilic bronchitis. Although no firm diagnosis was made on this occasion, symptoms occurred at a time when influenza was prevalent and there was a good response to co-trimoxazole, suggesting that the recurrent symptoms were due to infection.
The withdrawal of inhaled corticosteroid at the time of the initial presentation of the patient resulted in an increase in symptoms and a change in airway responsiveness from normal (as typically seen in eosinophilic bronchitis $[3,8]$ ) to mildly hyperresponsive (consistent with asthma). These changes were associated with worsening of sputum eosinophilia, suggesting that the development of airway hyperresponsiveness only occurred when airway inflammation was allowed to become more severe. This supports the notion that, in some patients, eosinophilic bronchitis and asthma represent ends of a spectrum of the same disease, and that eosinophilic bronchitis can be an early manifestation of asthma [8].

Our patient achieved a complete and long-lasting remission after a short course of prednisone. This is not a previously recognized feature of eosinophilic bronchitis nor is it a common feature of chronic asthma. The transient nature of the abnormality presented here might be a consequence of a brief exposure to an environmental allergen or toxin, although the season of onset of our patient's symptoms makes it unlikely that pollen hypersensitivity was responsible. An alternative and intriguing possibility is that early aggressive treatment reversed the inflammatory process before it became self-perpetuating.

In conclusion, this report demonstrates the occurrence in sequence of eosinophilic bronchitis alone, eosinophilic bronchitis with methacholine airway hyperresponsiveness, resolution with a short course of prednisone, followed by recurrence of cough of different cause. This interpretation of events would not have been possible without serial measurements of sputum cell counts.

\section{References}

1. Popov T, Gottschalk R, Kolendowicz R, Dolovich J, Powers P, Hargreave FE. The evaluation of a cell dispersion method of sputum examination. Clin Exp Allergy 1994; 24: 778-783.

2. Juniper EF, Cockcroft DW, Hargreave FE. Histamine and methacholine inhalation tests: a laboratory tidal breathing protocol. Lund, Sweden AB Draco (subsidiary of AB Astra), 1994.

3. Gibson PG, Dolovich J, Denburg J, Ramsdale EH, Hargreave FE. Chronic cough: eosinophilic bronchitis without asthma. Lancet 1989; i: 1346-1348.

4. Pin I, Gibson PG, Kolendowicz R, et al. Use of induced sputum cell counts to investigate airway inflammation in asthma. Thorax 1992; 47: 25-29.

5. Pizzichini E, Pizzichini MMM, Efthimiadis A, et al. Indices of inflammation in induced sputum: reproducibility and validity of cell and fluid phase measurements. Am J Respir Crit Care Med; 1996: 154.

6. Fahy JV, Liu J, Wong H, Boushey HA. Cellular and biochemical analysis of induced sputum from asthmatic and healthy subjects. Am Rev Respir Dis 1993; 147: 11261131.

7. Hargreave FE, Popov T, Kidney J, Dolovich J. Sputum measurements to assess airway inflammation in asthma. Allergy 1993; 48: 81-83.

8. Gibson PG, Hargreave FE, Girgis-Gabardo A, Morris M, Denburg JA, Dolovich J. Chronic cough with eosinophilic bronchitis: examination for variable airflow obstruction and response to corticosteroid. Clin Exp Allergy 1995; 25: $127-132$. 